\title{
A Numerical Analysis of the Combustion and the Study of the Exhaust Gases Resulting therefrom in the Marine Engines
}

\begin{abstract}
CATALIN FAITAR, FEIZA MEMET*, NICOLAE BUZBUCHI
Maritime University of Constanta, Faculty of Naval Electromechanics, 104 Mircea cel Batran Str., 900663, Constanta, Romania

Combustion inside diesel engine cylinders is the critical factor that controls the emission and combustion gases. Fuel injection in the engine cylinder is the decisive factor in the combustion of diesel engines and, consequently, combustion can be effectively controlled if the fuel injection process is efficiently controlled. From this perspective, the simulation of the complex processes of fuel injection in diesel engines in various situations can make a positive contribution to the optimization of marine propulsion systems. Also, correct dimensioning of the injection system components and its optimization and, implicitly, the combustion parameters, can have positive results in the context of reducing the impact of combustion gases of internal combustion engines, on the greenhouse effect and global warming.
\end{abstract}

Keywords: combustion, engine, modelling, injection, exhaust gases

The emergence and development of computing techniques, particularly electronic computers, have been instrumental in developing modelling. That's why in the last two decades the models have exploded. In parallel and in connection with these, numerical computational algorithms have been developed and perfected which have solved the complex systems of differential equations resulting from the modelling of the engine inside processes [1-3]. In this way, the core of the research activity migrated from the experimental sphere to the theoretic-applicative one. The complexity of the elaborated models and their performances have now allowed the transition from the estimated to the predictive stage, their use being now indispensable in the research design activity [4].

Modelling involves the creation of a system from theoretical hypotheses that allow simulation of the actual processes under study. It comprises two important steps:

-physical modelling identifies the particularities of the system or process under investigation and based on assumptions assigns different importance levels to the phenomena describing the real system, realizing a system of equations whose complexity depends on the nature of the phenomena and the degree of detail with which they are analyzed;

-mathematical modelling is the subsequent step which, through modifications made to the initial equation system, allows for calculation procedures that can be applied to obtain useful results with the least possible computational effort and with the highest accuracy [5-7].

The combustion process in diesel engines is the most complex and difficult to address. The complexity of the phenomena to be modeled is very high. One approach to combustion modelling in diesel engines develop modelling chemical phenomena involving:

- modelling the fuel;

- modelling the chemical reactions of combustion and polluting emissions [8].

Chemical reactions are considered only stoichiometric ones in the hypothesis of perfect combustion of an ideal fuel with the chemical formula $\mathrm{C}_{\mathrm{H}} \mathrm{H}_{\mathrm{O}} \mathrm{O}$ where the $\mathrm{m}, \mathrm{n}, \mathrm{r}$ ratios can be also rational numbers. These reactions were complemented with the $\mathrm{CO}_{2}$ dissociation reaction at equilibrium that is considered to be the most important. Chemical modelling may also take into account the
Zeldovich mechanism that allows the determination of the amount of NO but the solving of the equations becomes very difficult and it is necessary to know the contingencies of the reaction velocities [10].

The injection, ignition and expansion are the most important processes in the engine cycle and can be treated simultaneously.

The ignition reactions are modelling using the stoichiometric equation [3]:

$$
\left\{\begin{array}{l}
\mathrm{C}+\mathrm{O}_{2}=\mathrm{CO}_{2} \\
\mathrm{H}_{2}+\frac{1}{2} \mathrm{O}_{2}=\mathrm{H}_{2} \mathrm{O} \\
\mathrm{S}+\mathrm{O}_{2}^{2}=\mathrm{SO}_{2}
\end{array}\right.
$$

and the reaction of dissociation of $\mathrm{CO}_{2}$ :

$$
\delta \mathrm{CO}_{2} \rightarrow \delta \mathrm{CO}+\frac{\delta}{2} \mathrm{O}_{2}
$$

where:

$$
K_{P c 0} \sqrt{\frac{p}{v}}=\frac{1-\delta}{\delta\left(\frac{1}{2} \delta\right)^{\frac{1}{2}}}
$$

and

$$
\delta=\sqrt[3]{\frac{2}{K_{P C O}^{2}} \frac{v}{p}}
$$

or

$$
\begin{gathered}
\delta=\delta^{\prime} \sqrt[3]{\frac{v}{p}} \text { using approximation: } \\
\left\{\begin{array}{l}
\nu=v+\frac{1}{2} v \cong 1 \\
\delta^{\prime} \cong 10^{-7}(T-1400)^{2}
\end{array}\right.
\end{gathered}
$$

The mass of $\mathrm{CO}$ obtained from dissociation is too small and is considered negligible but is very important for heat balance when temperature rise over $1400 \mathrm{~K}$.

$$
d Q_{\dot{d}}=\delta \cdot d m_{\mathrm{CO}_{2}} \cdot Q_{\mathrm{co}}[\mathrm{J}]
$$


where $Q_{C O}=279231[\mathrm{kj} / \mathrm{kg}]$.

The fuel was carefully thought about a chemically pure substance thathas formula $\mathrm{C}_{\mathrm{H}} \mathrm{O}$, This approach allowed to calculate the products of combustion according to the reaction:

$$
\begin{gathered}
\mathrm{C}_{n} \mathrm{H}_{m} \mathrm{O}_{r}+\left(n+\frac{m}{4}-\frac{r}{2}\right) \mathrm{O}_{2}+\frac{79}{21}\left(n+\frac{m}{4}-\frac{r}{2}\right) N_{2} \Rightarrow \\
\Rightarrow n \mathrm{CO}_{2}+\frac{m}{2} \mathrm{H}_{2} \mathrm{O}+\frac{79}{21}\left(n+\frac{m}{4}-\frac{r}{2}\right) N_{2}
\end{gathered}
$$

The ignition delay time can be calculated with the formula proposed by Baert [3]:

$$
\tau_{a a}=\tau_{a o}+k_{1} p^{-n 1} \exp \left(\frac{E}{\Re T}\right)+k_{2} p^{-n 2}[\mathrm{~ms}]
$$

The injection law is considered a linear one, but has been taken into account a supplementary parabolic and polynomial one (second degree). The fuel instantaneous vaporization is also treated only from the energetically point of one.

$$
d Q_{v}=\left[L v+c_{l}\left(T_{s}-T_{l}\right)\right] d m_{i v j}[\mathrm{~J}]
$$

whit $L v$-latent vaporization heat; $C_{1}$ - specific heat; $T_{s}$ vaporization temperature; $T_{1}$ - temperature of fuel.

During the combustion period the heat release is obtained using two models:

-based on Wiebe's functions,

-the fuel rate Whitehouse-Way model.

The first model proposes an empirical formula for the rate of heat release based on the analysis of the experimental diagram according to the expression:

$$
\begin{aligned}
& \left(m_{b}\right)_{i}>\left(m_{p r}\right)_{i} \frac{d Q_{b}}{d \alpha}=a_{p} \frac{\Delta Q_{p r}}{\Delta \alpha_{p}}\left(M_{p r}+1\right)\left(\frac{\alpha}{\Delta \alpha_{p r}}\right)^{M_{\theta r}} e^{-a_{p}\left(\frac{\alpha}{\Delta \alpha_{v r}}\right)^{N_{p r}+1}}+ \\
& +a_{\dot{d}} \frac{\Delta Q_{\dot{d}}}{\Delta \alpha_{\dot{d}}}\left(M_{\dot{d}}+1\right)\left(\frac{\alpha}{\Delta \alpha_{\dot{d}}}\right)^{M_{\dot{d}}} e^{-a_{\dot{d}}\left(\frac{\alpha}{\Delta \alpha_{\dot{d}}}\right)^{X_{\dot{d}} \sharp}}
\end{aligned}
$$

The numeric calculation expressed heat release in a small step according to the formula:

$$
d Q c=\left(d Q_{j} d \alpha\right) m_{i v j}[\mathrm{~J}]
$$

This formula permits the heat release calculation for any time step of calculus.

The second method calculates heat using two expressions for fuel preparation and reaction rates.

The fuel preparation rate is given by:

$$
\frac{d m_{p r}}{d \alpha}=c d_{i n j}^{1-x} m_{u}^{x} p_{O_{2}}^{m} \quad[\mathrm{Kg} / \mathrm{deg}]
$$

and the reaction rate by:

$$
\frac{d m_{b}}{d \alpha}=\frac{60 k^{\prime} p_{O_{2}}}{n \sqrt{T}} e^{\frac{-E}{T}} \int\left(d m_{p r}-d m_{b}\right)[\mathrm{Kg} / \mathrm{deg}]
$$

$-m_{i n}[\mathrm{~kg}]$-total mass of fuel injected,

$-m_{u}^{i n}[\mathrm{~kg}]$-the mass of unburned fuel;

$m_{2}=m_{i x j}-\int\left(d m_{p r}\right) d \alpha$.

$-c$ and $d$-constants,

- $\mathrm{p}_{02}[\mathrm{bar}]$ - partial pressure of oxygen,

$-E[j]$-activation energy,

- $k^{\prime}$ - constant,

- $n$ - engine speed.

The numeric calculations using the rate fuel model consider that:

$$
\left(m_{i n j}\right)_{i-1}=\sum_{1}^{n-1} \frac{d m_{i n j}}{d \alpha} \Delta \alpha
$$

Similarly, the total fuel prepared and burnt in the cylinder is given by:

$$
\begin{aligned}
& \left(m_{p p}\right)_{i-1}=\sum_{1}^{i-1} d m_{p r} \Delta \alpha \\
& \left(m_{b}\right)_{i-1}=\sum_{1}^{i-1} d m_{b} \Delta \alpha
\end{aligned}
$$

In principle, average values of $m_{\text {in }}$ and $m_{\text {f }}$ for step would be the logical values to use, but this demands a knowledge of the conditions at the end of the step, which can only be obtained by an iterative procedure. If the change in the values during the step is small enough, relative to the absolute values, which is usually true for the step size used in these calculations, the initial values could be used.

For the first step of the process, when $m_{i n j}$ and $m_{u}$ are very small, this condition is not valid and use of initial values alone would underestimate preparation. For this reason, as $m_{\text {in }}$ is usually known and specified as data, the final value of $m_{\text {inj }}$ for the step may be used. Then:

$$
m_{i p j}=\left(m_{i p j_{j}}\right)_{i} \text { and } m_{u}=\left(m_{i p}\right)_{i}-\left(m_{p r}\right)_{i-1}
$$

gives the preparation rate during the step as:

$$
\left(\frac{d m_{p r}}{d \alpha}\right)_{i}=k\left(m_{i v y}\right)_{i}^{1-x}\left[\left(m_{i p j}\right)_{i}-\left(m_{p r}\right)_{i-1}\right]^{k} p_{O_{2}}^{m}[\mathrm{Kg} / \mathrm{deg}]
$$

and the total fuel prepared:

$$
\left(m_{p r}\right)_{i}=\left(m_{p r}\right)_{i-1}+\left(\frac{d m_{p r}}{d \alpha}\right)_{i} \Delta \alpha[\mathrm{Kg}]
$$

To obtain the fuel burnt in the step is used the reaction rate equation:

$$
\frac{d m_{b}}{d \alpha}=\frac{60 k^{\prime} p_{O_{2}}}{n \sqrt{T}} e^{\frac{-E}{T}}\left[\left(m_{i v i}\right)_{i}-\left(m_{b}\right)_{i-1}\right][\mathrm{Kg} / \mathrm{deg}]
$$

The fuel burnt is:

$$
\left(m_{b}\right)_{i}=\left(m_{b}\right)_{i-1}+\left(\frac{d m_{b}}{d \alpha}\right)_{i} \Delta \alpha[\mathrm{Kg}]
$$

If $\left(m_{b}\right)_{i}<\left(m_{p r}\right)_{i}$ there is insufficient fuel prepared to hold and the fuel burnt in the step is:

$$
d m_{c}=\left(m_{b}\right)_{i} \Delta \alpha[\mathrm{Kg}]
$$

If however , there is insufficient prepared fuel in the cylinder for combustion to proceed in this way and combustion is assumed to be controlled by the rate of preparation and fuel burnt is the:

$$
d m_{c}=\left(m_{p r}\right)_{i} \Delta \alpha[\mathrm{Kg}]
$$

Using the mass of fuel burnt in each step of the cycle calculation can be determined the value of heat release $\mathrm{dQ}$ :

$$
d Q_{c}=d m_{c} Q_{i}[\mathrm{~J}]
$$

there $Q_{1}$ is the lower specific heat value of fuel [5].

\section{Experimental part}

Exhaust gas components measuring methods and evaluation

There are various ways of measuring the components in the exhaust gas. Not only the measuring equipment, but 
also the measurement procedures and the sampling technique are important in obtaining reliable results.

-NOx-is measured by two methods, the chemiluminescence analyzer (CLA) approved for certification and the electrochemical sensor(ECS) used in almost all portable instruments.

- $\mathrm{CO}$ and $\mathrm{CO}_{2}$-are usually measured with an infrared (IR) technique. Because this is an optical- light technique, the analyzers are also sensitive to other gas components.

-s0x -There are several methods of measuring SOx; infrared (IR), ultraviolet (UV) or ECS cells.

-Smoke and Opacity - Objective measurements can be carried out in the form of fractional sampling or unstack instruments. The most common methods of measuring smoke are:

-Bosch Smoke Number (Scale 0-10);

-Bacharach Smoke Number (Scale 0-9);

-Hartridge smoke value (unit: \% Hartridge);

-Ringelmann Number (Scale 0-5);

-Opacity in general (various instruments).

Annual emission reduction level by 2050 and new emission level is presented in figure 1.

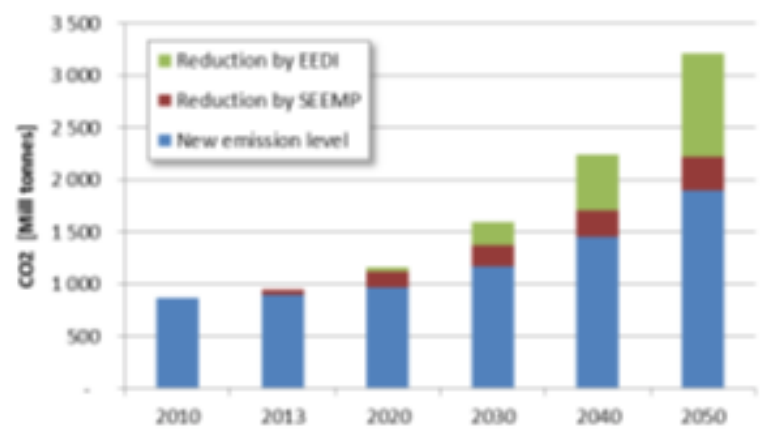

Fig. 1. Annual emission reduction level by 2050 and new emission level [9]

Mitsubishi-UE MDE 7UEC85LSII is a two-stroke, slow speed and reversible engine, with a constant overcharging pressure that develops a rated output of $27020 \mathrm{~kW}$ at a speed of $76 \mathrm{rpm}$, the ship shifting with a maximum speed of $16 \mathrm{kN}$ (knots). MITSUBISHI type 7UEC85LSII two-stroke engine has big bore size and a total power output up to $20000 \mathrm{~kW}$, being part of the category of high efficiency slow engines (fig. 2) [9]

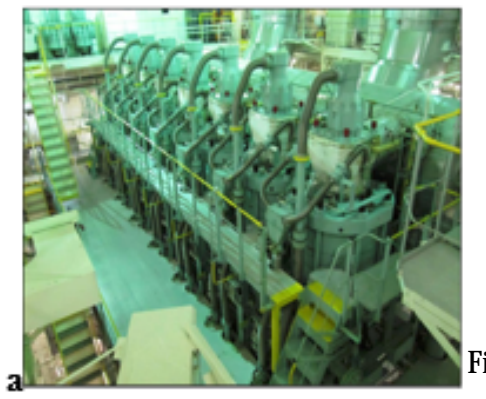

g. 2. Mitsubishi 7UEC85LSI main engine: (a) side

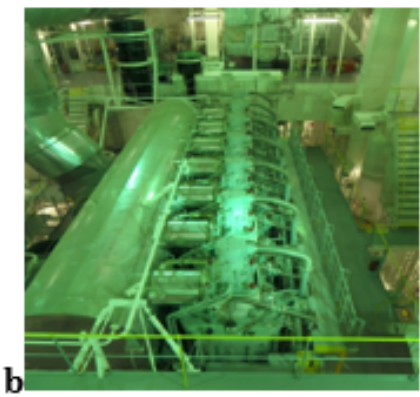
picture; (b) top picture [real photo onboard VLCC ship of 305000 dwt] [9]
Table 1 present the main characteristics of the engine.

Table 1

MAIN ENGINE CHARACTERISTICS

\begin{tabular}{|c|c|}
\hline Characteristics & Value \\
\hline Bore & $850 \mathrm{~mm}$ \\
\hline Stroke & $3150 \mathrm{~mm}$ \\
\hline Number of cylinders & 7 \\
\hline NCR power & $27020 \mathrm{~kW}$ \\
\hdashline Speed & $22965 \mathrm{~kW}$ \\
\hdashline & $76 \mathrm{rmm}$ \\
\hline
\end{tabular}

Consider that the ship is equipped with the engine which has an actual specific fuel consumption SFC $=171 \mathrm{~g} / \mathrm{kWh}$ and the conversion factor $C_{f}=3.1144$ For the calculation of the EEOI index we apply the formula below [8]:

$$
E E O I=\frac{\left(P_{M E} \cdot C_{f} \cdot S F C\right)+\left(P_{A E} \cdot C_{f} \cdot S F C\right)}{V_{\text {ref }} \cdot \Delta[t C O 2 / t \times \text { mile }]}
$$

where:

$-P_{M E}=27000 \mathrm{~kW}$ - main engine power for the speed of 16 knots;

- $P_{A=}=1100 \mathrm{~kW}$ - auxiliary engine power;

$-S F C=171 \mathrm{~g} / \mathrm{kWh}$ - specific fuel consumption;

$-\mathrm{V}_{\text {ref }}=16$ knots;

$-\Delta \stackrel{\text { ref }}{=} 305000 \mathrm{dwt}$ - ship capacity in tonnes;

- $\mathrm{C}_{\mathrm{f}}=3.1144$ - conversion factor.

The index for the speed 0 - 16 knots range was calculated and the values were obtained in table 2 .

Table 2

EEOI VALUES FOR THE SHIP OF $305000 \mathrm{dwt}$

\begin{tabular}{|c|c|c|}
\hline $\begin{array}{c}\text { Ship speed } \\
{[\mathbf{k n o t s}]}\end{array}$ & $\begin{array}{c}\text { Propulsion } \\
\text { power [kW] }\end{array}$ & $\begin{array}{c}\text { EEOI } \\
{[\text { tCO2 } / \boldsymbol{t} \text { x mile }]}\end{array}$ \\
\hline 0 & 0 & 0 \\
\hline 1 & 30 & 1.9731 \\
\hline 2 & 1828 & 2.5563 \\
\hline 3 & 3626 & 2.750699 \\
\hline 4 & 5424 & 2.847899 \\
\hline 5 & 7222 & 2.906219 \\
\hline 6 & 9020 & 2.945099 \\
\hline 7 & 10818 & 2.972871 \\
\hline 8 & 12616 & 2.993699 \\
\hline 9 & 14414 & 3.009899 \\
\hline 10 & 16212 & 3.022859 \\
\hline 11 & 18010 & 3.033463 \\
\hline 12 & 19808 & 3.042299 \\
\hline 13 & 21606 & 3.049776 \\
\hline 14 & 23404 & 3.056185 \\
\hline 15 & 25202 & 3.061739 \\
\hline 16 & 27000 & 3.066599 \\
\hline & & \\
\hline
\end{tabular}

In figure3 is presented the EEOI index vs ship speed.

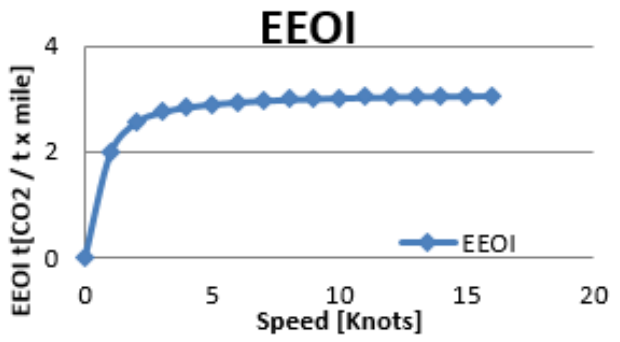

Fig. 3. EEOI index vs ship speed 


\section{Modelling}

In the next 3D modelling process, injection will be simulated in a diesel internal combustion engine with compression ignition. Cylinder geometry will be represented in a section to reduce the modelling area and reduce the time to calculate the solution. [10]. Calculations and simulation will be performed at scale for a small and generic engine, and simulation will begin from the intake valve closing at initial conditions of $3.45 \mathrm{bar}$ and $404 \mathrm{~K}$. The mass percent of the fuel is: $\mathrm{O}_{2}=0.1369, \mathrm{~N}_{2}=0.7473, \mathrm{CO}_{2}=$ $0.0789,0_{2}=0.0369$

Diesel fuel is injected at 4 degrees crankshaft rotations before compression. Combustion in the engine will be performed at a nominal rotation of $76 \mathrm{rpm}$. The results recorded will be assumed in this 3D section. In fig. 4 is presented the geometry configuration (a) and the discretization (b) of Mitsubishi engine cylinder.
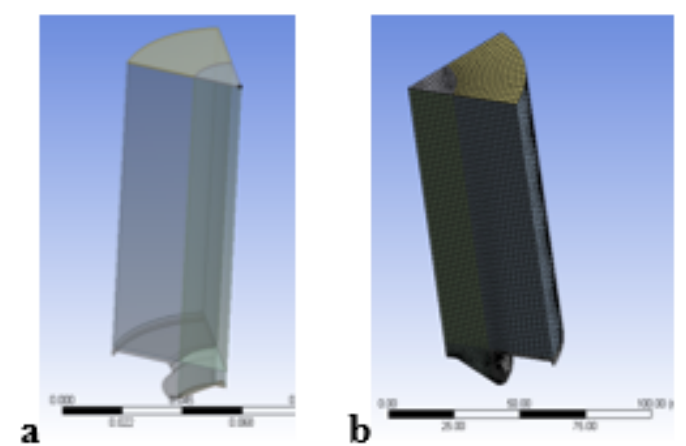

Fig. 4. Mitsubishi engine cylinder: (a) geometry configuration; (b) discretization

Were used the predetermined data from the injection determination program and the fuel chemistry. Space and surface conditions have been created for the user's choice. In the initialization submenu were introduced the values of the initial condition of the simulation.

Injection and combustion in diesel engine chambers was studied in detail over time giving the importance of this process in performance and overall efficiency of the engine.

\section{Results and discussions}

This database can use to make a comparative validation, and this kind of comparison is legitimate as long as the phenomena present variations, of course, taking in consideration the geometry of the combustion chamber, the injection and compression parameters, and assumptions basic models. The phenomenology of the present study was realized by using simulation software Ansys. In figure 5 are presented the particle traces colored by temperature $[K]$, in figure 6 the particle traces colored by velocity $(\mathrm{m} / \mathrm{s})$, in figure 7 the contours of static temperature $[\mathrm{K}]$, in figure 8 the contours of velocity
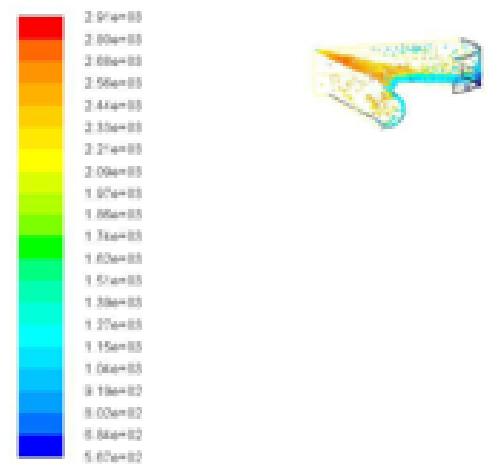

Fig. 5. Particle traces colored by temperature $[\mathrm{K}]$
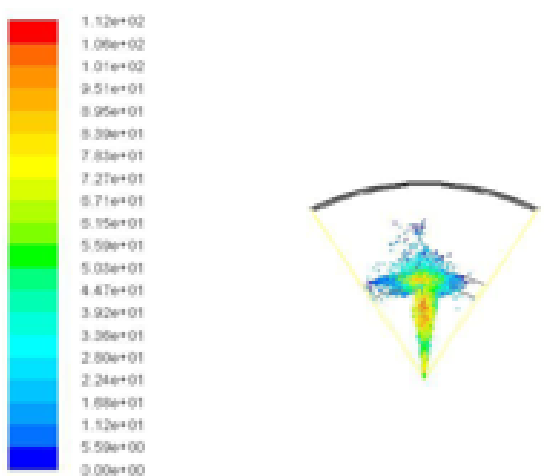

Fig. 6. Particle tracs colored by velocity $[\mathrm{m} / \mathrm{s}]$
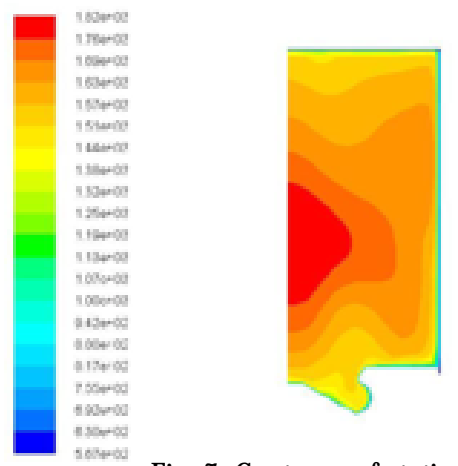

Fig. 7. Contours of static temperature [K]
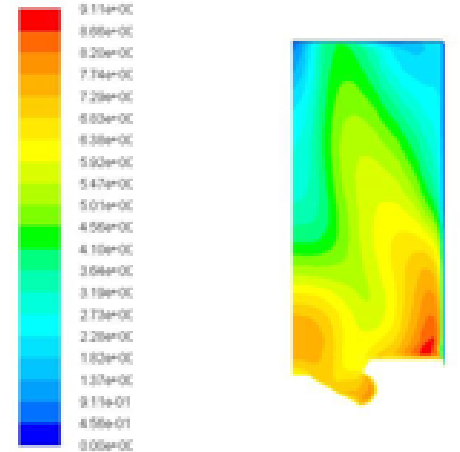

Fig. 8. Contours of velocity magnitude $[\mathrm{m} / \mathrm{s}]$
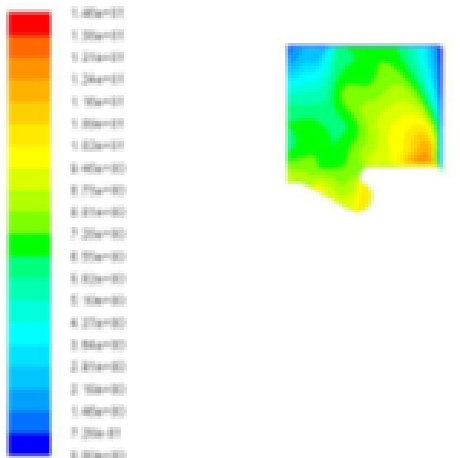

Fig. 9. Contours of velocity magnitude $[\mathrm{m} / \mathrm{s}]$

magnitude $[\mathrm{m} / \mathrm{s}]$, and in figure 9 the contours of velocity magnitude $[\mathrm{m} / \mathrm{s}]$.

This theoretical work represent an extremely detailed inventory of the thermodynamic models and the dynamic phenomena occurring in combustion chambers of diesel engines, as follows:

-deepening multidimensional combustion models, accompanied by very close benchmarking of interdisciplinary phenomenology accompanying these complex processes.

-presentation precepts FEA modelling (Finite Element Analysis) of chemical combustion and fuel mixture model with non-premix used in the simulation. 
-develop model CFD analysis (Computational Fluid Dynamics) of the combustion chamber with the deduction of all results of engineering analysis and pressures of the combustion chamber resulting from the combustion of fuel, speeds, temperatures, distribution density, viscosity, diffusion coefficients of different chemical species, thermal conductivity, specific heat, Prandtl number distribution, entropy, internal energy, total energy, kinetic energy of turbulence, turbulence intensity, velocity, response rate, molecular weight, the total enthalpy of each species, humidity, mass fractions of chemical species, molar concentration distribution of chemical species.

-interpretation of simulation results in terms of their comparison with reference works in the field, resulting in good correlation with experiments, thus proving the viability and accuracy of the model created.

\section{Conclusions}

The meshing network was denser in the central area where high velocity gradients were recorded. Following the simulation in the Ansys program, graphics and animations were provided with information on the trajectory and temperature of injected fuel particles.

The model used does not take into account the interaction between the particles, which makes the results in the immediate vicinity of the nozzle to be not sufficiently accurate. In addition, the particles were considered spherical to simplify the calculation of the drag coefficient, and the turbulence model used is too restrictive and not adaptive, being heavily influenced by the imposed simplistic assumptions.

Approached jets cases are quite different from jets in diesel engines, and therefore the results must be applied with discernment.
Correct dimensioning of the injection system components and its optimization and, implicitly, the combustion parameters, can have positive results in the context of reducing the impact of combustion gases of internal combustion engines, on the greenhouse effectand global warming.

\section{References}

1.STAN, LC, Simulation of air pollution due to marine engines, 2017 IOP Conf. Ser.: Mater. Sci. Eng. 227, 012121, p.726-735.

2.BALDI, F, Modelling, Analysis and Optimization of Ship Energy Systems (Thesis for the degree of doctor of Engineering: Sweden), Chalmers University of Technology, 2016.

3.BODOLAN, D, Emission control of two-stroke low-speed diesel engines, Constantza Maritime Center Ceronav, 2005, p.15-22.

4.BENSON, RS, WHITEHOUSE, ND, Internal combustion engine, Pergamon Press, London, 1983.

5.BODOLAN, D, Metode de control i reducere a emisiilor poluante ale sistemelor energetice navale, Universitatea Maritimã Constanka, 2003.

6.MAN B \& W Diesel A/S. How to deal with Emission Control, Teglholmsgade 41, DK - 2450, Copenhagen, SV Denmark.

7.SLIWA, A., GROS, D., SANDU, A.V., NABIALEK M., Optimization and Numerical Analysis of Mechanical Properties of Connecting Rod in the Internal Combustion Engine, Rev. Chim.(Bucharest), 69, no.10, 2018, p.2813-2815.

8.*** INTERNATIONAL MARITIME ORGANIZATION, Interim guidelines on the method of calculation of the energy efficiency design index for new ships mepc.1/Circ.681 17 August 2009

9.*** MITSUBISHI HEAVY INDUSTRIES, Ltd, Technical Book, Horaisan Ship.

10.SAIFUL KARIM MD, IMO Technical Measures in Reducing Greenhouse Gas Emission from Ships: Perspectives of Asian Countries, Queensland University of Technology, Brisbane, Australia, ASLI Working Paper, November 2013.

Manuscript received: 5.09 .2018 